\title{
Maturação in vitro de oócitos bovinos em meios suplementados com quercetina e seu efeito sobre o desenvolvimento embrionário
}

\author{
[In vitro maturation of bovine oocytes in medium supplemented with quercetin, and its \\ effect on embryonic development] \\ S. Guemra ${ }^{1,3}$, P.S. Monzani ${ }^{1,3}$, E.S. Santos ${ }^{1}$, R. Zanin ${ }^{1}$, O.M. Ohashi ${ }^{2}$, \\ M.S. Miranda ${ }^{2}$, P.R. Adona ${ }^{1,3^{*}}$ \\ ${ }^{1}$ Agropecuária Laffranchi - Tamarana, PR \\ ${ }^{2}$ Universidade Federal do Pará - Belém, PA \\ ${ }^{3}$ Universidade Norte do Paraná - Londrina, PR
}

\begin{abstract}
RESUMO
A quercetina é um flavonoide, amplamente encontrada em frutas, vegetais, grãos, flores, com elevada concentração no vinho tinto, e tem sido caracterizada funcionalmente pela atividade antioxidante. Para avaliação da maturação nuclear e do desenvolvimento embrionário bovino, os oócitos foram maturados por $22 \mathrm{~h}$ na presença de quercetina $(0,4,2,10$ e $50 \mu \mathrm{M})$, cisteamina $(100 \mu \mathrm{M})$ e na ausência dos antioxidantes. Os oócitos maturados foram corados com Hoechst para avaliação da maturação in vitro. Para avaliação do desenvolvimento embrionário, os oócitos foram fertilizados e cultivados in vitro, as taxas de desenvolvimento embrionário foram determinadas no sétimo dia de cultivo e o percentual de eclosão e o número de células dos embriões no oitavo dia. Os níveis de glutationa (GSH) dos oócitos foram mensurados por emissão de fluorescência com $\mathrm{CMF}_{2} \mathrm{HC}$. A porcentagem de maturação nuclear $( \pm 89 \%)$ não diferiu entre os grupos. $\mathrm{O}$ desenvolvimento embrionário variou entre os tratamentos, $\mathrm{O}$ percentual de blastocisto foi superior $(\mathrm{P}<0,05)$ nos grupos tratados com $0,4,2,10$ e $50 \mu \mathrm{M}$ de quercetina $(56,9,59,5,53,6$ e $49,6 \%$, respectivamente) e com $100 \mu \mathrm{M}$ de cisteamina $(50,4 \%)$ em relação ao grupo controle $(42,3 \%)$. Na comparação entre os dois antioxidantes, a quercetina $(0,4$ e $2 \mu \mathrm{M})$ foi superior na produção de embriões (56,9 e 59,5\%, respectivamente) em comparação com cisteamina (50,4\%). As taxas de embriões eclodidos foram similares $(\mathrm{P}>0,05)$ entre os grupos $( \pm 63,0 \%)$. O número médio de células dos embriões também foi similar entre os grupos $( \pm 233)$. Os níveis intracelulares de GSH foram superiores nos oócitos maturados com cisteamina, mas similares entre os oócitos tratados com quercetina e o controle. A suplementação da maturação in vitro com antioxidantes melhora as taxas de blastocistos. A quercetina foi superior à cisteamina, que, por sua vez, foi superior ao controle. Mas os níveis de GSH foram superiores somente nos oócitos tratados com cisteamina.
\end{abstract}

Palavra-chave: antioxidante, bovino, embrião, quercetina e oócito

\begin{abstract}
Quercetin is a flavonoid widely found in fruit, vegetables, grains and flowers, with a high concentration in red wine, and has been functionally characterized by its antioxidant activity. For assessment of nuclear maturation and bovine embryo, oocytes were matured for $22 \mathrm{~h}$ in the presence of quercetin $(0.4,2,10$ and $50 \mu \mathrm{M})$, cysteamine $(100 \mu \mathrm{M})$ and in the absence of antioxidants. The matured oocytes were stained with Hoechst to evaluate the in vitro maturation. To assess embryonic development, oocytes were fertilized and cultured in vitro and rates of embryo development were obtained in the seventh day of culture and the percentage of hatching and the number of cells on eighth day embryos. The levels of glutathione $(G S H)$ of the oocytes were measured by fluorescence emission with $\mathrm{CMF}_{2} \mathrm{HC}$. The percentage of nuclear maturation ( $\pm 89 \%$ ) did not differ between groups. Embryonic development varied between treatments, the
\end{abstract}

Recebido em 16 de maio de 2012

Aceito em 5 de maio de 2013

*Autor para correspondência (corresponding author)

E-mail: paulo_adona@yahoo.com.br 
percentage of blastocyst was higher $(P<0.05)$ in the groups treated with $0.4,2,10$ and $50 \mu M$ of quercetin (56.9, 59.5, 53.6 and 49.6\%, respectively) and $100 \mu M$ cysteamine (50.4\%) compared to the control group (42.3\%). Comparing the two antioxidants, quercetin $(0.4$ to $2 \mu M)$ was superior in embryo production (56.9 and 59.5\% respectively) compared with cysteamine (50.4\%). The rates of hatched embryos were similar $(P>0.05)$ between groups $( \pm 63.0 \%)$. The average number of embryo cells was also similar in both groups $( \pm 233)$. The intracellular GSH levels were higher in oocytes matured with cysteamine, but similar between the oocytes treated with quercetin and control. The supplementation of matured in vitro with antioxidants improves blastocyst rates. Quercetin was greater than cysteamine, which in turn was superior to the control. However, GSH levels were higher in oocytes treated only with cysteamine.

Keywords: Antioxidant, bovine, embryo, quercetin and oocyte

\section{INTRODUÇÃO}

As condições de maturação in vitro (MIV) dos oócitos bovinos são essenciais para a produção de embriões. A MIV é influenciada por diferentes fatores, como atmosfera gasosa, meio de cultivo, temperatura, suplementação proteica e fatores de crescimento (Santos et al., 2002; Sutton-McDowall et al., 2012). Avanços significantes foram obtidos modificando-se os meios de cultivo embrionários, o que resultou no aumento da taxa na produção in vitro (PIV) de embriões. No entanto, vários trabalhos têm sido realizados visando à maior eficiência da técnica (De Matos et al., 2002; Schwarz et al., 2010; Adona et al., 2011; Dey et al., 2012), visto que a capacidade de fecundação e de desenvolvimento embrionário depende da maturação nuclear e citoplasmática do oócito (Ferreira et al., 2008). A maturação dos oócitos é caracterizada por uma série de transformações bioquímicas e estruturais no núcleo e citoplasma, sendo essenciais para o processo da fecundação e subsequente desenvolvimento embrionário.

Durante a PIV de embriões, ocorre a geração das espécies reativas de oxigênios (EROs), oriundas da tensão de oxigênio, exposição à luz e excesso de manipulação (Guerin et al., 2001). O aumento na produção de $\mathrm{H}_{2} \mathrm{O}_{2}$ em embriões de camundongos foi observado, quando expostos à luz por mais de cinco minutos (Goto et al., 1992). A presença equilibrada das EROs e antioxidantes tem impacto positivo para a PIV de embriões (Guerin et al., 2001; Andrade et al., 2010). Portanto, o uso de antioxidantes em sistemas de alta concentração de oxigênio (20\% de $\mathrm{O}_{2}$ ) é considerado um fator importante para a PIV de embriões, devido às suas ações na diminuição dos efeitos danosos causados pelas EROs.
As EROs são espécies químicas, tais como átomos, moléculas ou fragmento de moléculas, que apresentam pelo menos um elétron não compartilhado na camada de valência. Quando as espécies reativas são formadas a partir do oxigênio, elas são chamadas de EROs, no entanto outros tipos de espécies reativas podem surgir do nitrogênio, carbono ou enxofre (Silva $e t$ al., 2011). As espécies reativas de maior relevância são as EROs, pois são produzidas pelo metabolismo fisiológico dos embriões (Guerin $e t$ al., 2001; Silva et al., 2011). Quando em baixas concentrações, as EROs desempenham importante papel fisiológico in vitro, como a promoção das competências dos oócitos e do desenvolvimento do embrião (Blondin et al., 1997; Guerin et al., 2001). Quando uma quantidade excessiva de EROs é liberada, ocorre o estresse oxidativo (Andrade et al., 2010). A abundância das EROs pode ter efeitos deletérios sobre a função celular, conduzindo aos danos oxidativos dos componentes intracelulares, os quais podem induzir a apoptose (Yang et al., 1998; Guerin et al., 2001). O uso de antioxidantes visa balancear a formação das EROs e manter as funções fisiológicas dos oócitos, contrapondo o aumento indiscriminado das EROs na MIV.

A quercetina é um flavonoide do grupo dos compostos polifenólicos, amplamente encontrado nas frutas, vegetais, grãos, flores, com elevada concentração no vinho tinto, e que apresenta ação antioxidante. $\mathrm{O}$ seu desempenho terapêutico no combate ao estresse oxidativo tem sido mencionado por vários autores (Peres et al., 2000; Behling et al., 2004; Liu et al., 2010) e se dá em três etapas diferentes: na iniciação pela interação com íons superóxido, na formação de radicais hidroxila por quelar íons de ferro e na 
peroxidação lipídica por reagir com radicais peróxido de lipídeos (Afanas'ev et al., 1989). O radical hidroxila e o ânion superóxido estão envolvidos no dano tecidual por iniciarem a peroxidação lipídica e a disrupção da matriz intersticial (Silva et al., 2011).

Vários trabalhos utilizando a quercetina foram realizados com o intuito de identificar os efeitos fisiológicos e as atividades biológicas desse flavonoide para fins terapêuticos em humanos, no entanto não há informação disponível sobre os efeitos da quercetina sobre a maturação in vitro de oócitos bovinos. Neste estudo, foi investigado o uso da quercetina durante a fase de maturação in vitro e o seu efeito sobre a taxa de produção de blastocisto e os níveis de glutationa nos oócitos maturados.

\section{MATERIAL E MÉTODOS}

Os produtos para PIV de embriões foram adquiridos da Sigma Chemical Company, St Louis, MO, EUA, a menos que especificados de outro modo.

Os ovários de fêmeas bovinas foram coletados no frigorífico logo após o abate e transportados em solução fisiológica estéril ( $\mathrm{NaCl} 0,9 \%)$ acrescida de $50 \mu \mathrm{g} / \mathrm{mL}$ de gentamicina a $30^{\circ} \mathrm{C}$. No laboratório, os ovários foram lavados em $\mathrm{NaCl} 0,9 \%$, e os folículos com diâmetro de $2-$ $8 \mathrm{~mm}$ foram aspirados com auxílio de uma agulha $(1,20 \mathrm{X}$ 40mm) conectada a uma seringa descartável de $10 \mathrm{~mL}$. O líquido folicular contendo os oócitos foi depositado em tubos cônicos de $50 \mathrm{~mL}$ e mantido em repouso para decantação por cinco minutos. $\mathrm{O}$ pellet contendo os oócitos foi adicionado a $5 \mathrm{~mL}$ de meio H199 (Meio 199 com 25mM de hepes acrescido de $50 \mu \mathrm{g} / \mathrm{mL}$ de gentamicina e $5 \%$ de soro fetal bovino - SFB) em uma placa de Petri, para a seleção dos oócitos sob estereomicroscópio. Somente oócitos classificados como graus I e II, contendo mais de três camadas de células do cumulus e citoplasma uniforme, foram utilizados para os experimentos.

A quercetina (Sigma, Q4951) foi preparada em solução estoque de $50 \mathrm{mg} / \mathrm{mL}$ em hidróxido de sódio $1 \mathrm{M}$, e a cisteamina (Sigma, C8397) foi preparada em solução estoque de $100 \mathrm{mg} / \mathrm{mL}$ em $\mathrm{H}_{2} \mathrm{O}$, aliquotadas em microtubos e estocadas a $20^{\circ} \mathrm{C}$.
Maturação in vitro (MIV): Após a classificação, os oócitos foram transferidos para o meio de maturação, constituído pelo Meio 199 (Sigma, M4530) suplementado com $10 \%$ de SFB, $5,0 \mu \mathrm{g} / \mathrm{mL}$ de LH (Lutropin-v, Vetrepharm), $0,5 \mu \mathrm{g} / \mathrm{mL}$ de FSH (Folltropin-v, Vetrepharm), $0,2 \mu \mathrm{M}$ de piruvato e $50 \mu \mathrm{g} / \mathrm{mL}$ de gentamicina. Os oócitos foram cultivados separadamente na presença de quercetina $(0,4,2,10$ e $50 \mu \mathrm{M})$, cisteamina $(100 \mu \mathrm{M})$ e na ausência dos antioxidantes (controle) durante 22 horas, em gotas de $100 \mu \mathrm{L}$ de meio de maturação sob óleo mineral, montadas em placa de Petri, a $38,5^{\circ} \mathrm{C}$ e atmosfera de $5 \%$ de $\mathrm{CO}_{2}$. Cada gota continha aproximadamente 20 oócitos.

Avaliação da MIV: Os oócitos foram desnudados (remoção das células do cumulus) em tubo de $5 \mathrm{~mL}$, com $0,3 \mathrm{~mL}$ de PBS (Nutricell) acrescida de $1 \%$ de SFB, e agitados no "vortex" por quatro minutos. Os ovócitos desnudos foram expostos ao corante Hoechst (33342), na concentração de $1 \mu \mathrm{g} / \mathrm{mL}$ em PBS, e incubados por cinco minutos, protegidos da luz. Após este período, foram lavados por três vezes em PBS e fixados entre lâmina e lamínula para avaliação quanto à taxa de MIV no microscópio de epifluorescência (Eclipse Ti Nikon - filtro UV-2A, com comprimento de onda de 330-380/420-700nm de absorção/emissão).

Os níveis de glutationa (GSH) intracelular nos oócitos bovinos foram determinados com marcador de fluorescência Cell Tracker Blue $\mathrm{CMF}_{2} \mathrm{HC}$ (4-clorometil-6, 8 - difluoro-7hidroxicumarina, Life Technologies, C12881). Para as avaliações, os oócitos foram desnudados em PBS-PVA (Álcool polivinílico, 0,05\%) e corados com $10 \mu \mathrm{M}$ de $\mathrm{CMF}_{2} \mathrm{HC}$ em PBS-PVA por 30 minutos em estufa de $\mathrm{CO}_{2}$ a $38,5^{\circ} \mathrm{C}$. Após coloração, os oócitos foram lavados três vezes e colocados em uma lâmina com $10 \mu \mathrm{L}$ de PBSPVA. A emissão de fluorescência foi capturada automaticamente (cinco segundos) com auxílio da câmera Infinity após a exposição na luz ultravioleta (filtro UV-2A) do microscópio Eclipse Ti Nikon. As imagens registradas foram analisadas usando-se o programa de análises de imagens da câmera Infinity (software V6.2.0).

Fecundação in vitro (FIV): Foi utilizado sêmen congelado de um mesmo touro (raça Nelore) e da mesma partida, o qual foi preparado segundo a 
técnica de gradiente de Percoll. Em um tubo de microcentrífuga, foram adicionados $400 \mu \mathrm{L}$ de Percoll $90 \%$ e, em seguida, $400 \mu \mathrm{L}$ de Percoll $45 \%$. O sêmen foi descongelado a uma temperatura de $37^{\circ} \mathrm{C}$ por 30 segundos, adicionado na porção superior do gradiente de Percoll e centrifugado por cinco minutos a 800 "g". Após a retirada do sobrenadante, foi adicionado $1 \mathrm{~mL}$ de meio TALP (Parrish et al., 1988), e uma nova centrifugação de dois minutos a 200 "g" foi realizada para remover o excedente do Percoll. A FIV foi feita em TALP com $2 \mu \mathrm{M}$ de penicilamina, $1 \mu \mathrm{M}$ de hipotaurina, $250 \mu \mathrm{M}$ de epinefrina, $20 \mu \mathrm{g} / \mathrm{mL}$ de heparina e $6 \mathrm{mg} / \mathrm{mL}$ de albumina sérica bovina (BSA - Sigma, A8806). Os espermatozoides $\left(2 \times 10^{6}\right.$ espermatozoides/ $\mathrm{mL}$ ) e os oócitos foram coincubados em gotas de $100 \mu \mathrm{L}$ de meio sob óleo mineral, montadas em placa de Petri, por um período de 18 horas.

Após a FIV, os oócitos foram desnudados com auxílio de um micropipetador de $50 \mu \mathrm{L}$ e transferidos para o meio de cultivo in vitro (CIV) fluido de oviduto sintético (SOF), suplementado com aminoácidos essenciais (BME) e não essenciais (MEM), 0,34mM de sódio tricitrato, 2,77mM de mioinositol (Holm et al., 1999), $3 \%$ de SFB, $4 \mathrm{mg} / \mathrm{mL}$ de BSA, ITS (insulina $5 \mu \mathrm{g} / \mathrm{mL}$, transferrina $5 \mu \mathrm{g} / \mathrm{mL}$ e selênio $5 \mathrm{ng} / \mathrm{mL}$ ) e aminoácidos (glicina $0,75 \mathrm{mg} / \mathrm{mL}$, alanina $0,15 \mathrm{mg} / \mathrm{mL}$ e glutamina $0,09 \mathrm{mg} / \mathrm{mL}$ ), em gotas de $100 \mu \mathrm{L}$ de meio com monocamada de células somáticas (cumulus). $\mathrm{O}$ cultivo in vitro foi feito em estufa de $\mathrm{CO}_{2}$, a $38,5^{\circ} \mathrm{C}$, em atmosfera de $5 \%$ de $\mathrm{CO}_{2}$ em ar.

Para avaliação do número de células dos embriões eclodidos no oitavo dia após fecundação, os embriões foram expostos ao corante Hoechst como descrito na avaliação dos oócitos. Após o método de coloração, os embriões foram fotografados (Infinity câmera software V6.2.0) no microscópio de epifluorescência para contagem do número de células.

Experimento I. Avaliação do efeito dos antioxidantes sobre a maturação nuclear. Os oócitos foram maturados separadamente na presença de quercetina $(0,4,2,10$ e $50 \mu \mathrm{M})$, cisteamina $(100 \mu \mathrm{M})$ e na ausência dos antioxidantes (controle) durante $22 \mathrm{~h}$ e avaliados quanto ao estádio de maturação nuclear.
Experimento II. Avaliação do efeito dos antioxidantes na maturação in vitro sobre $\mathrm{o}$ desenvolvimento embrionário. Os oócitos foram cultivados separadamente na presença de quercetina $(0,4,2,10$ e $50 \mu \mathrm{M})$, cisteamina $(100 \mu \mathrm{M})$ e controle durante $22 \mathrm{~h}$. Após a MIV, os oócitos foram submetidos à FIV (18h) seguida pelo CIV. As taxas de clivagem foram determinadas no segundo dia de cultivo (D2), o desenvolvimento dos embriões em estádio de blastocistos foi determinado no sétimo dia (D7) do CIV, e a eclosão e o número de células dos embriões no oitavo dia (D8). Todos os sistemas de cultivo foram feitos em estufa de $\mathrm{CO}_{2}$, a $38,5^{\circ} \mathrm{C}$, e em atmosfera de $5 \%$ de $\mathrm{CO}_{2}$.

Experimento III. Avaliação dos níveis glutationa (GSH) intracelular em oócitos imaturos e maturados in vitro com marcador de fluorescência Cell Tracker Blue. Os oócitos em estádio de vesícula germinativa (VG) e maturados na presença de quercetina $(2 \mu \mathrm{M})$, cisteamina e na ausência dos antioxidantes (MIV) foram corados com Cell Tracker Blue para avaliação dos níveis de GSH. Para controle da técnica, um grupo de oócitos imaturos e outro maturado foram expostos a $0,009 \%$ de peróxido de hidrogênio $\left(\mathrm{H}_{2} \mathrm{O}_{2}\right)$ por 30 minutos junto ao corante e avaliados quanto aos níveis de GSH.

As análises estatísticas foram realizadas com o programa BioEstat 2. Para os resultados significativos nas análises de variância, foi utilizado o Bonferroni como procedimento de comparações múltiplas entre os tratamentos. O nível de significância adotado foi de 5\% para evidenciar diferenças entre os tratamentos.

\section{RESULTADOS}

No experimento I, foram utilizados 512 oócitos, distribuídos em sete tratamentos e três repetições (Tab. 1). O percentual de oócitos em vesícula germinativa (VG) após aspiração folicular foi de $100 \%$ para o controle zero hora (Fig. 2A), e o percentual de oócitos que completaram a maturação nuclear (metáfase II) foi de aproximadamente $89,0 \%$ para os grupos tratados com quercetina $(0,4,2,10$ e $50 \mu \mathrm{M})$, cisteamina $(100 \mu \mathrm{M})$ e controle $(22 \mathrm{~h})$, não havendo variação significativa $(\mathrm{P}>0,05)$ nas taxas de maturação nuclear. 
Tabela 1. Efeitos da quercetina e da cisteamina sobre a maturação in vitro de oócitos bovinos

\begin{tabular}{lcccc}
\hline Tratamentos & $\begin{array}{c}\text { Oócitos } \\
\mathrm{N}^{\circ}\end{array}$ & $\begin{array}{c}\text { VG } \\
\mathrm{N}^{\circ}(\% \pm \mathrm{dpm})\end{array}$ & $\begin{array}{c}\mathrm{RVG} \\
\mathrm{N}^{\circ}(\% \pm \mathrm{dpm})\end{array}$ & $\begin{array}{c}\text { Metáfase II } \\
\mathrm{N}^{\circ}(\% \pm \mathrm{dpm})\end{array}$ \\
\hline Quercetina $0,4 \mu \mathrm{M}$ & 78 & $0(0,0 \pm 0,0) \mathrm{b}$ & $7(9,0 \pm 6,0) \mathrm{a}$ & $71(91,0 \pm 6,0) \mathrm{a}$ \\
Quercetina $2 \mu \mathrm{M}$ & 71 & $0(0,0 \pm 0,0) \mathrm{b}$ & $7(9,8 \pm 7,3) \mathrm{a}$ & $64(90,1 \pm 7,3) \mathrm{a}$ \\
Quercetina $10 \mu \mathrm{M}$ & 78 & $0(0,0 \pm 0,0) \mathrm{b}$ & $11(14,1 \pm 12) \mathrm{a}$ & $67(85,8 \pm 12) \mathrm{a}$ \\
Quercetina $50 \mu \mathrm{M}$ & 72 & $0(0,0 \pm 0,0) \mathrm{b}$ & $10(13,9 \pm 11) \mathrm{a}$ & $62(86,1 \pm 11) \mathrm{a}$ \\
Cisteamina & 71 & $0(0,0 \pm 0,0) \mathrm{b}$ & $6(8,5 \pm 7,1) \mathrm{a}$ & $65(91,5 \pm 7,1) \mathrm{a}$ \\
Controle $(22$ horas & 67 & $0(0,0 \pm 0,0) \mathrm{b}$ & $7(10,4 \pm 7,5) \mathrm{a}$ & $60(89,5 \pm 7,5) \mathrm{a}$ \\
Controle $(0$ hora) & 75 & $75(100 \pm 0,0) \mathrm{a}$ & $0(0,0 \pm 0,0) \mathrm{b}$ & $0(0,0 \pm 0,0) \mathrm{b}$ \\
\hline
\end{tabular}

Letras diferentes na mesma coluna indicam diferença $(\mathrm{P}<0,05)$ entre tratamentos. Desvio-padrão médio $(\mathrm{dpm})$ de três repetições. Oócitos em vesícula germinativa (VG), rompimento da VG (RVG) e maturados (metáfase II).

Para a realização do experimento II, foram utilizados 1.684 oócitos, distribuídos em seis tratamentos e sete repetições, os quais estão descritos na Tab. 2. Pelas análises dos resultados, as taxas de clivagem foram similares $(\mathrm{P}>0,05)$ entre os grupos, obtendo-se uma porcentagem média de aproximadamente $80,0 \%$ para os oócitos tratados com quercetina, de $76,3 \%$ para os tratados com cisteamina e de $76,6 \%$ para os do grupo controle. $\mathrm{O}$ desenvolvimento embrionário variou entre os tratamentos (Tab. 2), o percentual de blastocisto D7 foi superior $(\mathrm{P}<0,05)$ nos grupos tratados com $0,4,2,10 \mathrm{e}$ $50 \mu \mathrm{M}$ de quercetina $(56,9,59,5,53,6$ e 49,6\%, respectivamente) e com $100 \mu \mathrm{M}$ de cisteamina $(50,4 \%)$ em relação ao grupo controle $(42,3 \%)$. $\mathrm{Na}$ comparação entre os dois antioxidantes, a quercetina $(0,4$ e $2 \mu \mathrm{M})$ foi superior $(\mathrm{P}<0,05)$ na produção de embriões $(56,9$ e $59,5 \%$, respectivamente) em comparação com a cisteamina $(50,4 \%)$, mas as concentrações de $10 \mu \mathrm{M}(53,6 \%)$ e $50 \mu \mathrm{M}(49,6 \%)$ de quercetina foram similares $(\mathrm{P}>0,05)$ às encontradas com a cisteamina $(50,4 \%)$. Nas comparações entre as concentrações de quercetina, a dose de $2 \mu \mathrm{M}$ $(59,5 \%)$ foi similar $(\mathrm{P}>0,05)$ à dose de $0,4 \mu \mathrm{M}$ $(56,9)$, mas diferiu $(\mathrm{P}<0,05)$ das concentrações de $10 \mu \mathrm{M}(53,6 \%)$ e $50 \mu \mathrm{M}(49,6 \%)$, que foram similares entre si. As concentrações de $0,4 \mu \mathrm{M}$
$(56,9)$ e $10 \mu \mathrm{M}(53,6 \%)$ de quercetina também apresentaram similaridade $(\mathrm{P}>0,05)$ na produção de embriões. As taxas de embriões eclodidos no dia oito após a FIV (Tab. 2) foram similares $(\mathrm{P}>0,05)$ entre os grupos, obtendo-se um percentual médio de aproximadamente $64,0 \%$ de eclosão com quercetina, $56,2 \%$ com cisteamina e $64,4 \%$ no grupo controle. O número de células dos embriões eclodidos (Tab. 2) também foi similar $(\mathrm{P}>0,05)$ entre os grupos, a média aproximada de células (Fig. 2A) foi de $238 \mathrm{com}$ quercetina, de 223 com cisteamina e de 225 no grupo controle.

No experimento III, foram utilizados 210 oócitos, distribuídos em seis tratamentos e três repetições (Fig. 1). Os oócitos imaturos $\mathrm{VG} / \mathrm{H}_{2} \mathrm{O}_{2} \quad(0,86)$ e VG $(1,00)$ apresentaram emissão de fluorescência inferior $(\mathrm{P}<0,05)$ aos oócitos submetidos à maturação $\mathrm{MIV} / \mathrm{H}_{2} \mathrm{O}_{2}$ $(1,31)$ e MIV $(1,67)$. Na comparação entre os grupos controle (MIV), quercetina $(2 \mu \mathrm{M})$ e cisteamina, o nível de GSH intracelular avaliado pela emissão de fluorescência (Fig. 2B) não diferiu significativamente $(\mathrm{P}>0,05)$ entre $\mathrm{O}$ controle $(1,67)$ e a quercetina $(1,64)$, mas ambos diferiram $(\mathrm{P}<0,05)$ do grupo com cisteamina $(1,76)$.

Tabela 2. Uso da quercetina e da cisteamina na maturação in vitro e seu efeito para a competência do desenvolvimento embrionário

\begin{tabular}{|c|c|c|c|c|c|}
\hline Tratamentos & $\begin{array}{c}\text { Oócitos } \\
\mathrm{N}^{\mathrm{o}}\end{array}$ & $\begin{array}{l}\text { Clivagem D2 } \\
\mathrm{N}^{\circ}(\% \pm \mathrm{dpm})\end{array}$ & $\begin{array}{c}\text { Blastocisto D7 } \\
\mathrm{N}^{\circ}(\% \pm \mathrm{dpm})\end{array}$ & $\begin{array}{l}\text { Eclosão D8 } \\
\mathrm{N}^{\circ}(\% \pm \mathrm{dpm})\end{array}$ & $\begin{array}{c}\text { Células D8 } \\
\text { No (Mín-Máx } \pm \text { dpm) }\end{array}$ \\
\hline $\mathrm{Q} 0,4 \mu \mathrm{M}$ & 295 & $241(81,6 \pm 10)$ & $168(56,9 \pm 3,3) \mathrm{ab}$ & $100(59,5 \pm 33)$ & $224(108-477 \pm 71)$ \\
\hline $\mathrm{Q} 2 \mu \mathrm{M}$ & 287 & $246(85,7 \pm 5,4)$ & $171(59,5 \pm 1,9) \mathrm{a}$ & $114(66,6 \pm 18)$ & $246(110-432 \pm 65)$ \\
\hline $\mathrm{Q} 10 \mu \mathrm{M}$ & 287 & $222(77,3 \pm 3,5)$ & $154(53,6 \pm 4,9) b c$ & $99(64,2 \pm 20)$ & $249(108-419 \pm 77)$ \\
\hline Q $50 \mu \mathrm{M}$ & 294 & $226(76,8 \pm 8,4)$ & $146(49,6 \pm 3,1) \mathrm{c}$ & $95(65,0 \pm 18)$ & $232(114-443 \pm 78)$ \\
\hline Cisteamina & 268 & $210(76,3 \pm 4,4)$ & $135(50,4 \pm 3,8) \mathrm{c}$ & $76(56,2 \pm 22)$ & $223(106-415 \pm 74)$ \\
\hline Controle & 253 & $194(76,6 \pm 7,9)$ & $107(42,3 \pm 4,2) \mathrm{d}$ & $69(64,4 \pm 13)$ & $225(108-425 \pm 79)$ \\
\hline
\end{tabular}

Letras diferentes na mesma coluna indicam diferença $(\mathrm{P}<0,05)$ entre tratamentos. Desvio-padrão médio (dpm) de sete repetições. Número mínimo e máximo (Mín-Máx) de célula dos embriões eclodidos. Diferentes concentrações de quercetina $(\mathrm{Q})$. 


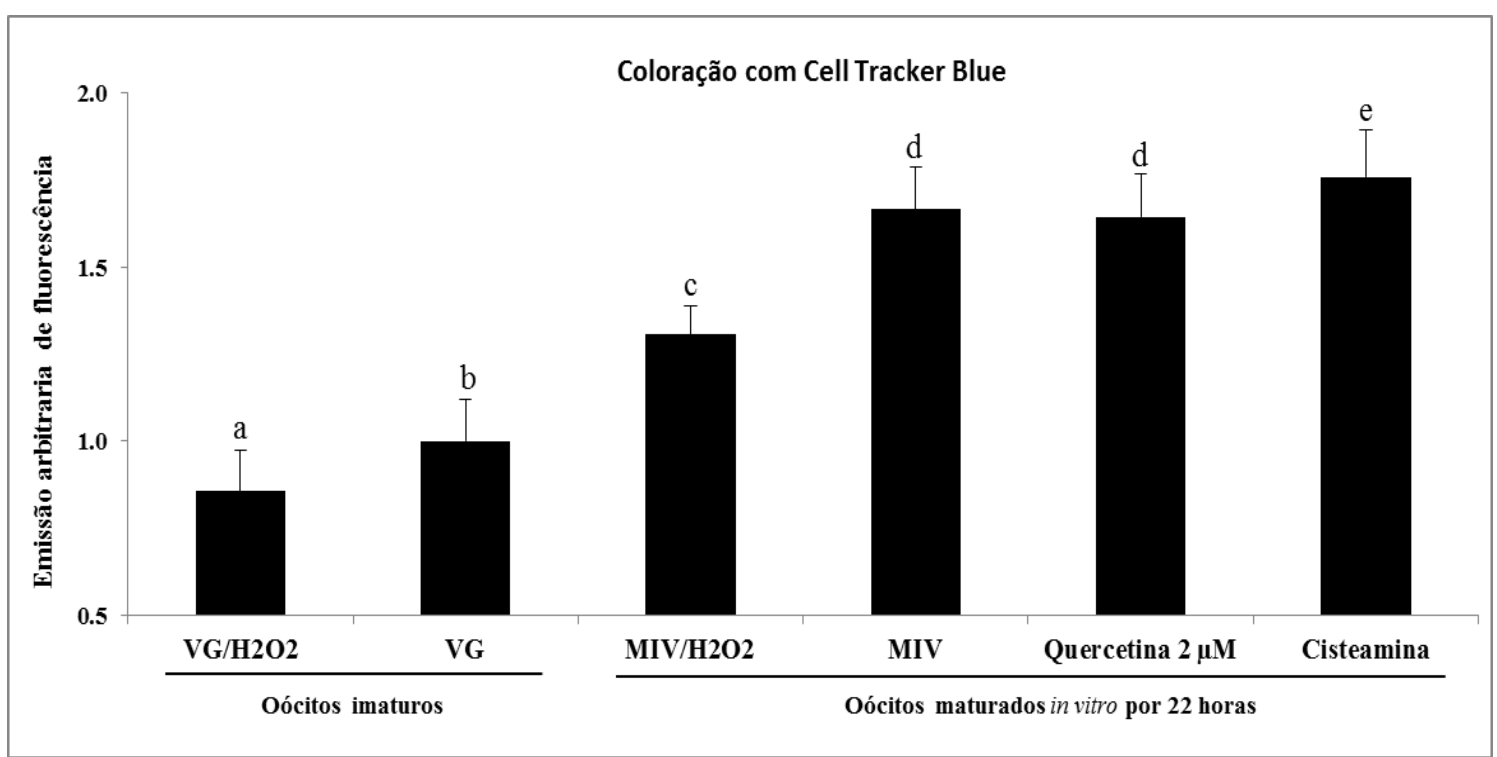

Figura 1. Níveis de glutationa (GSH) intracelular em oócitos bovinos avaliado com Cell Tracker Blue. Os oócitos em vesícula germinativa $\left(\mathrm{VG} / \mathrm{H}_{2} \mathrm{O}_{2}\right)$ e maturados $\left(\mathrm{MIV} / \mathrm{H}_{2} \mathrm{O}_{2}\right)$ foram tratados com $0,009 \%$ de peróxido de hidrogênio por 30 minutos. As barras com letras $\left({ }^{\mathrm{a}-\mathrm{e}}\right)$ diferentes indicam diferença $(\mathrm{P}<0,05)$ entre tratamentos. Resultados de três repetições.

(A)

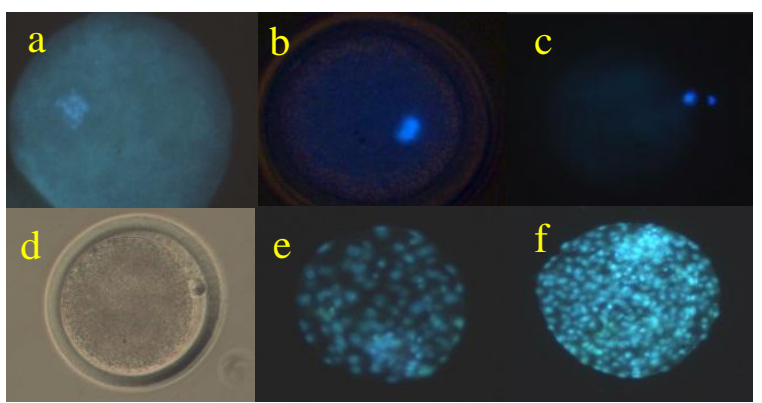

(B)

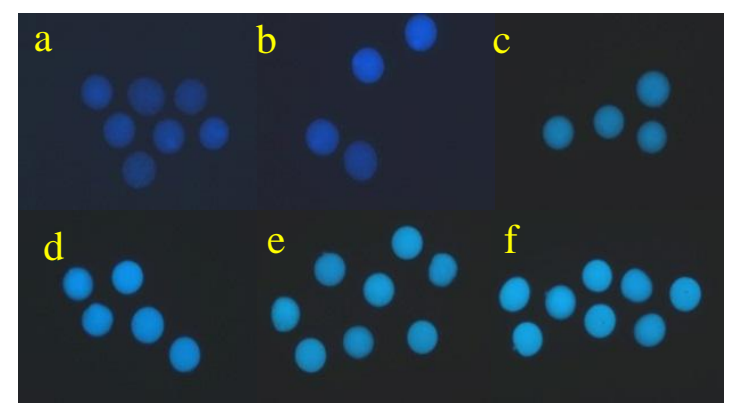

Figura 2. Coloração com Hoechst para avaliação da maturação e do número de células dos embriões (A). Oócito em vesícula germinativa (a), estádio intermediário (b), metáfase II (c), liberação do $1^{\circ}$ corpúsculo polar (d), embrião com \pm 110 células (e) e embrião com \pm 360 células (f). Intensidade de fluorescência do nível GSH intracelular em oócitos avaliados com Cell Tracker Blue (B). Oócitos $\mathrm{VG} / \mathrm{H}_{2} \mathrm{O}_{2}$ (a) VG (b) $\mathrm{MIV} / \mathrm{H}_{2} \mathrm{O}_{2}$ (c) MIV (d) quercetina (e) e cisteamina (f).

\section{DISCUSSÃO}

Durante a PIV de embriões, os oócitos e embriões são expostos a concentrações maiores de oxigênio do que aqueles produzidos in vivo. Esta maior exposição ao oxigênio faz com que ocorra uma produção de radicais livres. Altos níveis de radicais livres causam danos celulares, levando à perda de suas funções (Yang et al., 1998). Os radicais livres gerados in vitro, como o superóxido, o peróxido de hidrogênio e a hidroxila, reagem com as proteínas celulares, os lipídeos e o DNA, resultando na inativação enzimática, na peroxidação lipídica da membrana e em alterações do DNA (Andrade et al., 2010; Silva et al., 2011). A PIV de embriões em sistema com alta concentração de oxigênio atmosférico requer que os oócitos sejam protegidos contra o estresse oxidativo. A adição de antioxidante no meio de maturação na PIV de embriões visa reduzir os danos celulares causados pelo estresse oxidativo, durante a maturação oocitária, resultando no aumento das taxas de desenvolvimento embrionário. 
Os antioxidantes da classe dos flavonoides têm despertado um amplo interesse científico devido a suas propriedades sequestrantes de radicais livres (Behling et al., 2004). A quercetina é um flavonoide que tem propriedades quelantes e de sequestro de radicais de oxigênio, como o superóxido e a hidroxila, e também atua na inibição da enzima xantina oxidase e na peroxidação lipídica (Behling et al., 2004; Liu et al., 2010). O radical hidroxila e o ânion superóxido estão envolvidos no dano tecidual por iniciarem a peroxidação lipídica (Silva et al., 2011).

Várias propriedades terapêuticas da quercetina têm sido estudadas nas últimas décadas (Formica e Regelson, 1995; Larson et al., 2012), destacando-a como potencial antioxidante (Behling et al., 2004). O uso da quercetina na PIV de embriões bovinos e seu efeito sobre a maturação oocitária não se encontram reportados na literatura. No presente estudo, foi analisada a suplementação de diferentes concentrações $(0,4$, 2, 10 e $50 \mu \mathrm{M})$ de quercetina, durante a MIV, no intuito de investigar o potencial benefício na PIV de embriões. Paralelamente, foram delineados outros dois grupos experimentais: sem suplementação de antioxidante e outros suplementados com $100 \mu \mathrm{M}$ cisteamina, um antioxidante descrito na literatura para PIV de embriões (De Matos et al., 2002; Deleuze e Goudet, 2010), o qual é utilizado rotineiramente no laboratório.

No presente estudo, a suplementação dos meios de maturação com (quercetina e cisteamina) ou sem antioxidantes não provocou diferença nas taxas de maturação nuclear e de clivagem, o que sugere que não seria necessária a suplementação dos meios de maturação com os referidos antioxidantes. No entanto, a literatura descreve que a presença de antioxidante é essencial para a maturação de oócitos, particularmente para a maturação citoplasmática, necessária para o desenvolvimento embrionária (Furnus et al., 2008; Silva, et al., 2011). A maturação citoplasmática está diretamente relacionada com a taxa de desenvolvimento embrionário (Rizos et al., 2002), portanto, quando os oócitos foram tratados com os respectivos antioxidantes, obtiveram-se maiores taxas de desenvolvimento (Tab. 2). Estes resultados sugerem que a maturação suplementada com quercetina ou cisteamina pode afetar positivamente a proporção de blastocistos formados, mas não sua qualidade, visto que os embriões não apresentaram diferença $(\mathrm{P}>0,05)$ nas taxas de eclosão e nem no número de células dos blastocistos. De acordo com a literatura, a porcentagem de produção de embriões in vitro é afetada pela qualidade intrínseca dos oócitos e pela composição dos meios de maturação, e a qualidade dos embriões (blastocistos) é afetada pelo sistema de cultivo in vitro (Rizos et al., 2002; Sananmuang et al., 2011).

O uso de antioxidante no processo de MIV pode também influenciar negativamente o desenvolvimento de blastocistos (Guerin et al., 2001), pois a formação equilibrada de EROs exerce papel importante nos processos metabólicos da maturação oocitária e no desenvolvimento dos blastocistos (Sabatini et al., 1999). Neste estudo, foi observado que maior concentração de quercetina $(50 \mu \mathrm{M})$ apresentou a menor taxa $(49,7 \%)$ na produção de embriões em comparação com $2 \mu \mathrm{M}(59,6 \%)$, porém foi superior $(42,3 \%)$ à não adição de antioxidantes. Isto mostra que a suplementação equilibrada de antioxidante é fundamental para a PIV de embriões, em sistema de alta concentração de oxigênio atmosférico. E a concentração de antioxidante deve ser ajustada no sentido de manter o equilíbrio entre os benefícios na redução das EROs, bem como permitir que os processos de oxirredução dos oócitos sejam mantidos.

As prováveis causas do benefício na produção de embriões podem estar correlacionadas com a redução do estresse oxidativo durante o processo de MIV. Experimentos in vitro $\mathrm{e}$ in vivo demonstraram que quercetina e cisteamina são capazes de reduzir os danos celulares causados pelo estresse oxidativo (Liu et al., 2010; Deleuze e Goudet, 2010). A suplementação dos meios de maturação com cisteamina foi utilizada como padrão de antioxidante no sistema de produção, pois a cisteamina, quando adicionada no meio de maturação in vitro, estimula a síntese de glutationa (GSH) e melhora as taxas de desenvolvimento embrionário (De Matos et al., 2002). Esse aumento nos níveis de GSH também foi constatado neste estudo nos oócitos suplementados com cisteamina, sendo que a glutationa fornece a primeira linha de defesa contra as EROs em oócitos. 
Como já mencionado, a quercetina é capaz de reduzir os radicais livres (Braun et al., 2011), mas esse atributo da quercetina $(2 \mu \mathrm{M})$ não propiciou aumento ou redução nos níveis de GSH nos oócitos em relação ao grupo controle. A quercetina não é precursora da síntese de GSH e, portanto, não aumentaria diretamente sua síntese. Os níveis de GSH podem ser alterados $(\uparrow \downarrow)$ na presença de quercetina, dependendo do sistema de cultivo ou do tipo de estresse sofrido pelos oócitos. O sistema de maturação foi similar entre os grupos, e somente a cisteamina proporcionou aumento nos níveis de GSH, por ser precursora da síntese de GSH (De Matos et al., 2002), enquanto os cultivos com quercetina ou na ausência dos antioxidantes mantiveram níveis similares de GSH. Essa similaridade pode ser pela disponibilidade de aminoácidos precursores de GSH no meio de MIV e pode atuar estimulando a síntese de GSH. Segundo Furnus et al. (2008), a concentração de GSH aumenta em oócitos bovinos durante o processo da MIV decorrente dos aminoácidos disponíveis nos meios de maturação. Estudos mais aprofundados serão necessários para entender melhor as relações entre quercetina e a PIV de embriões e os níveis de GSH em oócitos bovinos.

\section{CONCLUSÃO}

A suplementação do meio de maturação in vitro com os antioxidantes quercetina ou cisteamina, em um sistema de alta concentração de oxigênio atmosférico, aumenta as taxas de produção de blastocistos. A suplementação de $2 \mu \mathrm{M}$ de quercetina apresentou a maior taxa de produção de blastocisto, sendo superior àquelas encontradas para a cisteamina e o controle. A cisteamina proporcionou aumento nos níveis de GSH, enquanto a quercetina manteve o mesmo nível encontrado no controle.

\section{AGRADECIMENTOS}

À Universidade Norte do Paraná (Unopar) e à Agropecuária Laffranchi, pelo apoio financeiro ao projeto.

\section{REFERÊNCIAS}

ADONA, P.R.; DE BEM, T.H.; MESQUITA, L.G. et al. Embryonic development and gene expression in oocytes cultured in vitro in supplemented prematuration and maturation media. Reprod. Domest. Anim., v.46, p.31-8, 2011.

AFANAS'EV, I.B.; DOROZHKO, A.I.; BRODSKII, A.V. et al. Chelating and free radical scavenging mechanisms of inhibitory action of rutin and quercetin in lipid peroxidation. Biochem. Pharmacol., v.38, p.1763-1769, 1989.

ANDRADE, E.R.; MELO-STERZA, F.A.; SENEDA M.M.; ALFIERI, A.A. Consequências da produção das espécies reativas de oxigênio na reprodução e principais mecanismos antioxidantes. Rev. Bras. Reprod. Anim., v.34, p.79-85, 2010.

BEHLING, E.B.; SENDÃO, M.C.; FRANCESCATO, H.D.C. et al. Flavonoide Quercetina: Aspectos gerais e ações biológicas. Alim. Nutr., v.15, p.285-292, 2004

BLONDIN, P.; COENEN, K.; SIRARD, M.A. The impact of reactive oxygen species on bovine sperm fertilizing ability and oocyte maturation. J. Androl., v.18, p.454-460, 1997.

BRAUN, K.F.; EHNERT, S.; FREUDE, T. et al. Quercetin protects primary human osteoblasts exposed to cigarette smoke through activation of the antioxidative enzymes HO-1 and SOD-1. Scientific World J., v.11, p.2348-2357, 2011.

DE MATOS, D.G.; HERRERA, C.; CORTVRINDT, R. et al. Cysteamine supplementation during in vitro maturation and embryo culture: a useful tool for increasing the efficiency of bovine in vitro embryo production. Mol. Reprod. Dev., v.62, p.203-209, 2002.

DELEUZE, S.; GOUDET, G. Cysteamine supplementation of in vitro maturation media: a review. Reprod. Domest. Anim., v.45, p.476-482, 2010.

DEY, S.R.; DEB, G.K.; HA, A.N. et al. Coculturing denuded oocytes during the in vitro maturation of bovine cumulus oocyte complexes exerts a synergistic effect on embryo development. Theriogenology, v.77, p.1064-1077, 2012.

FERREIRA, E.L.; VIREQUE, A.A.; ADONA. P.R. et al. Maturação citoplasmática de oócitos bovinos: aquisição de competência para o desenvolvimento. Rev. Bras. Reprod. Anim., v.32, p.172-181, 2008.

FORMICA, J.V.; REGELSON, W. Review of the biology of Quercetin and related bioflavonoids. Food Chem. Toxicol., v.33, p.1061-1080, 1995. 
FURNUS, C.; DE MATOS, D.G.; PICCO, S. et al. Metabolic requirements associated with GSH synthesis during in vitro maturation of cattle oocytes. Anim. Reprod. Sci., v.109, p.88-99, 2008.

GOTO, Y.; NODA, Y.; NARIMOTO, K. et al. Oxidative stress on mouse embryo development in vitro. Free Radic. Biol. Med., v.13, p.47-53, 1992.

GUERIN P.E.L.; MOUATASSIM, S.; MENEZO, Y. Oxidative stress and protection against reactive oxygen species in the pre-implantation embryo and its surroundings. Hum. Reprod. Update, v.7, p.175-189, 2001 .

HOLM, P.; BOOTH, P.J.; SCHMIDT, M.H. et al. High bovine blastocyst development in a static in vitro production system using SOFaa medium supplemented with sodium citrate and myo-inositol with or without serum-proteins. Theriogenology, v.52, p.683-700, 1999.

LARSON, A.J.; SYMONS, J.D.; JALILI, T. Therapeutic potential of quercetin to decrease blood pressure: review of efficacy and mechanisms. Adv. Nutr., v.3, p.39-46, 2012.

LIU, S.; HOU, W.; YAO, P. et al. Quercetin protects against ethanol-induced oxidative damage in rat primary hepatocytes. Toxicol. In vitro, v.24, p.516$522,2010$.

PARRISH, J.J.; SUSKO-PARRISH, J.; WINER, M.A.; FIRST, N.L. Capacitation of bovine sperm by heparin. Biol. Reprod., v.38, p.1171-1180. 1988.

PERES, W.; TUÑ́N, M.J.; COLLADO, P.S. et al. The flavonoid quercetin ameliorates liver damage in rats with biliary obstruction. J. Hepatol., v.33, p.742$750,2000$.

RIZOS, D.; WARD, F.; DUFFY, P. et al. Consequences of bovine oocyte maturation, fertilization or early embryo development in vitro versus in vivo: Implications for blastocyst yield and blstocyst quality. Mol. Repr. Development, v.61, p.234-248, 2002.
SABATINI, L.; WILSON, C.; LOWER, A. et al. Superoxide dismutase activity in human follicular fluid after controlled ovarian hyperstimulation in women undergoing in vitro fertilization. Fertil. Steril., v.72, p.1027-1034, 1999 .

SANANMUANG, T.; THARASANIT, T.; NGUYEN, C. et al. Culture medium and embryo density influence on developmental competence and gene expression of cat embryos Theriogenology. v.75, p.1708-1719, 2011.

SANTOS, S.S.D.; DANTAS, J.K.; MIRANDA, M.S et al. Cinética da maturação nuclear in vitro de oócitos bubalinos. Braz. J. Vet. Res. Anim. Sci., v.39, p.266270, 2002

SCHWARZ, K.R.; PIRES, P.R.; DE BEM, T.H. et al. Consequences of nitric oxide synthase inhibition during bovine oocyte maturation on meiosis and embryo development. Reprod. Domest. Anim., v.45, p.75-80, 2010

SILVA, G.M.; ARAÚJO, V.R.; DUARTE A.B.G. et al. Papel dos antioxidantes no cultivo in vitro de células ovarianas. Rev. Bras. Reprod. Anim., v.35, p.315-326, 2011.

SUTTON-McDOWALL, M.L.; FEIL, D.; ROBKER, R.L. et al. Utilization of endogenous fatty acid stores for energy production in bovine preimplantation embryos. Theriogenology. v.77, p.1632-41, 2012.

YANG, H.W.; HWANG, K.J.; KWON, H.C. et al. Detection of reactive oxygen species (ROS) and apoptosis in human fragmented embryos. Hum. Reprod., v.13, p.998-1002, 1998. 